\begin{tabular}{|c|c|c|}
\hline Iso 1 is & $\begin{array}{c}\text { Bulletin of Pharmaceutical Sciences } \\
\text { Assiut University }\end{array}$ & \\
\hline 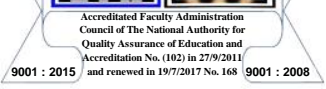 & $\begin{array}{c}\text { Website: http://bpsa.journals.ekb.eg/ } \\
\text { e-mail: bullpharm@aun.edu.eg }\end{array}$ & $\begin{array}{l}\text { BULL. PHARM. SCI. } \\
\text { Assiut Univ. }\end{array}$ \\
\hline
\end{tabular}

\title{
THE STUDY OF REYNOUTRIA SACHALINENSIS PLANT RAW MATERIAL FATTY ACID COMPOSITION
}

\author{
Abdulrazzaq Yasir Hussain Alrikabi, Viktoriia Protska, Oleksandra Kyslychenko and Iryna \\ Zhuravel \\ Department of Chemistry of Natural Compounds and Nutritiology, National University of \\ Pharmacy, Kharkiv, Ukraine
}

\begin{abstract}
The aim of the work was to study the qualitative composition and determine the quantitative content of fatty acids of roots, leaves, herb and flowers of Sakhalin (giant) knotweed (Reynoutria sachalinensis ( $F$. Schmidt) Nakai) by gas chromatography In Reynoutria sachalinensis roots and flowers 12 fatty acids were identified. In the herb 13 fatty acids and in the leaves 14 fatty acids have been identified. At least six fatty acids are classified as unsaturated fatty acids. About 70-80\% of the content in Reynoutria sachalinensis roots and leaves dry powder were unsaturated fatty acids. Saturated and unsaturated fatty acids in herb and flowers of the studied plant accumulated almost equally. The dominant fatty acid in Reynoutria sachalinensis roots was linoleic acid (40.90\%), in leaves - linolenic (37.20\%), in herb - arachidonic (37.05\%), in flowers - palmitic (37.20\%). In addition, Reynoutria sachalinensis herb had a high content of erucic acid that equaled $8.30 \%$. The obtained results allow to deepen the knowledge about the fatty acid composition of the raw materials of Reynoutria sachalinensis, to establish the relationship between pharmacodiological action and the fatty acid composition of the raw materials, and will be used in the development of drugs based on it.
\end{abstract}

\section{INTRODUCTION}

Fatty acids are chemically aliphatic longchain alkanes or alkenes with a methyl group at one end and a carboxyl group at the other. Natural fatty acids usually have up to thirty paired carbon atoms ${ }^{1-3}$. In the form of triglycerides, these compounds are a source of energy for the body, as well as perform thermoregulatory and protective functions ${ }^{2}$. In the pharmaceutical industry, fatty acids are widely used as excipients in the production of emulsions and remedies with liposomes ${ }^{2}$.

Polyunsaturated fatty acids are pharmacologically active, they are also called polyenes, which have several unsaturated bonds between carbon atoms. There are $\omega-3$ and $\omega-6$ unsaturated fatty acids according to the position of the unsaturated bonds. These acids cannot be synthesized in the human body and are essential compounds. These include monoic oleic, gondoic, erucic and polyene - linoleic and linolenic acids ${ }^{3}$. They affect metabolism, reduce inflammation, improve histological parameters of the intestinal mucosa, reduce the atherogenic index, as well as reduce the risk of heart attacks and strokes ${ }^{1 \& 2 \& 4}$.

Reynoutria sachalinensis (F. Schmidt) Nakai is a Far Eastern member of the Polygonaceae L. family, native to Sakhalin, the Kuril Islands, Korea, Taiwan, China, and $\mathrm{Japan}^{5-7}$. Due to confusion in the taxonomy, this plant has several nomenclature names, the most famous of which are Sakhalin knotweed or giant knotweed (Polygonum sachalinensis F. Schmidt and Fallopia sachalinensis (F.Schmidt) Ronse Decr. $)^{5 \& 6 \& 8 \& 9}$. This plant was introduced to Europe in the nineteenth century. Due to its rapid spread and resistance to adverse environmental factors, Reynoutria 
sachalinensis has become an invasive plant and today can often be found as a weed along roads, near railroad tracks and abandoned buildings. However, it is also cultivated as an ornamental, fodder and honey plant ${ }^{6 \& 10}$.

According to the literature data, all parts of Reynoutria sachalinensis accumulate essential oil, sterols ${ }^{9 \& 10}$, roots - anthraquinones (emodin, fiscion, rhein, citrerosein, falacinol, questin, vanicosides $\mathrm{A}$ and $\mathrm{B})^{10}$, roots, stems, and leaves - procyanidins, catechin, epicatechin, chlorogenic and caffeic acids ${ }^{6,8}$, leaves and stems - chlorophylls and carotenoids $\quad(\alpha-$ and $\beta$-carotene, $\beta$ cryptoxanthin, xanthophyll, lutein, zeaxanthin $^{10}$, flowers - flavonoids $^{6}$. Glycosides of the flavonoids luteolin, quercetin, kaempferol and stilbene resveratrol, piceid and astringin were identified by HPLC in the leaves and stems of this plant by Polish scientists ${ }^{6 \& 8-10}$. According to Moldovan scientists, the aeriel part of the plant contains essential amino acids lysine, isoleucine, leucine, methionine, phenylalanine, valine, threonine and up to $22 \%$ protein 9 .

Russian scientists determined the content of linoleic (6.04\%), linolenic (6.78), myristic (10.86\%), palmitic (3.61\%) and eicosapentaenoic $(2.57 \%)$ acids in aboveground part of Reynoutria sachalinensis by LCMS . A group of Japanese and Chinese scientists found that saturated fatty acids, including palmitic $(39.2 \%)$ and stearic $(20.0 \%)$ acids, predominated in Reynoutria japonica. In addition, this plant raw material contained $4.5 \%$ lauric, $8.6 \%$ myristic, $1.4 \%$ arachic and $1.7 \%$ behenic acids. Among unsaturated fatty acids, only oleic acid was detected $(6.9 \%)^{7}$. Other information on the fatty acid composition of the genus Reynoutria Houtt. was not found in the literature.

Reynoutria sachalinensis in Southeast Asia is used as a laxative, anti-inflammatory, antiviral, antibacterial analgesic, antipyretic, antioxidant, antiulcer and antitumor agent ${ }^{6,8,10}$. In traditional Chinese medicine, this plant is used to treat infectious and inflammatory diseases of the upper respiratory tract, toothache, skin ulcers and burns, hypertension, hemorrhoids, hepatitis, gallstones and osteomyelitis ${ }^{6 \& 10 \& 12}$.

Pharmacopoeia of the People's Republic of China recommends Reynoutria japonica roots as an anti-inflammatory, hepatoprotective and antitumor agent ${ }^{5}$. According to the Pharmacopoeia of Japan, this plant raw material is used in the treatment of inflammation and burns of the skin, jaundice and hyperlipidemia ${ }^{12}$. In 2017, Reynoutria japonica roots were included in the list of Chinese traditional medicinal plants of the European Pharmacopoeia ${ }^{12 \& 13}$. Reynoutria sachalinensis is related to Reynoutria japonica, but is not included in any pharmacopoeia of the world. In Ukraine, this plant is unofficial due to lack of data on its chemical composition and biological action. Therefore, to deepen the knowledge about the qualitative composition and quantitative content of biologically active compounds (BAC) of Reynoutria sachalinensis, it was advisable to study the fatty acid composition of its aboveground and underground organs.

The aim of the research was to study the qualitative composition and determine the quantitative content of fatty acids in the roots, leaves, herb and flowers of Reynoutria sachalinensis.

\section{MATERIALS AND METHODS}

\section{Plant Raw Material}

For the experiment, air-dried, crushed roots, leaves, herb and flowers of Reynoutria sachalinensis were used. Plant raw material was harvested in 2019-2020 in the Kharkiv region.

Plant samples of Reynoutria sachalinensis were identified by Professor Iryna Zhuravel, Department of Chemistry of Natural Compounds and Nutriciology, National University of Pharmacy, Ukraine. The voucher specimen was deposited at National University of Pharmacy (Ukraine) with certain number 2108/2020. 


\section{Research methodology and chromatography conditions}

The study of the qualitative composition and determination of the fatty acids quantitative content after methylation was performed by gas chromatography using "Selmichrome-1" gas chromatograph with a flame ionization detector. Fatty acid methyl esters were identified by retention time compared to standard samples of methyl esters of saturated and unsaturated fatty acids manufactured by "Sigma-Aldrich".

Hexane fraction from the studied samples of Reynoutria sachalinensis plant raw material, methylation of which was carried out according to a modified method of Peisker was used for the analysis ${ }^{14}$.

During the chromatographic analysis a 2.5 $\mathrm{m}$ long chromatographic column with an inner diameter of $4 \mathrm{~mm}$ was used. The stationary phase was inerton, treated with $10 \%$ diethylene glycol succinate. The following parameters were set on the device: column thermostat temperature $180^{\circ} \mathrm{C}$, evaporator temperature $230^{\circ} \mathrm{C}$, detector temperature $220^{\circ} \mathrm{C}$, carrier gas flow rate (nitrogen) equaled $30 \mathrm{~cm}^{3} / \mathrm{min}$, sample volume was $2 \mathrm{~mm}^{3}$ of methyl ester solution fatty acids in hexane. Quantitative content of individual fatty acids was calculated by the method of internal normalization. The fatty acids content was calculated (as \% of total amount) in terms of peaks area using the generally accepted procedure ${ }^{14 \& 15}$.

\section{RESULTS AND DISCUSSION}

According to the results of the experiment, 12 fatty acids were identified in the roots and flowers of Reynoutria sachalinensis, 13 fatty acids were identified in herb, and 14 fatty acids were identified in leaves. Of these, there were 6 unsaturated fatty acids were identified in roots and flowers, and 7 fatty acids were identified in leaves and herb. Gas chromatograms of methyl esters of fatty acids from roots, leaves, herb and flowers of Reynoutria sachalinensis are shown in Figure 1-4

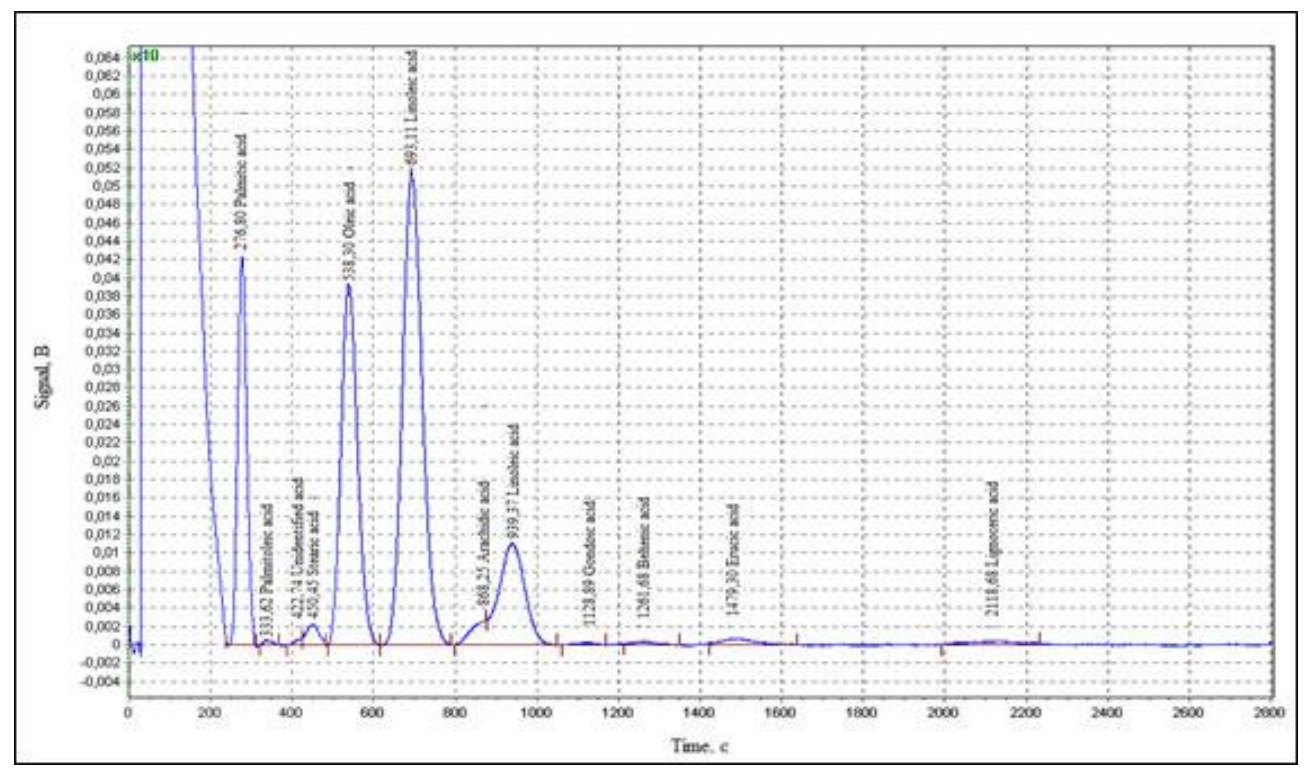

Fig. 1: Chromatographic profile of fatty acid methyl esters of Reynoutria sachalinensis roots 


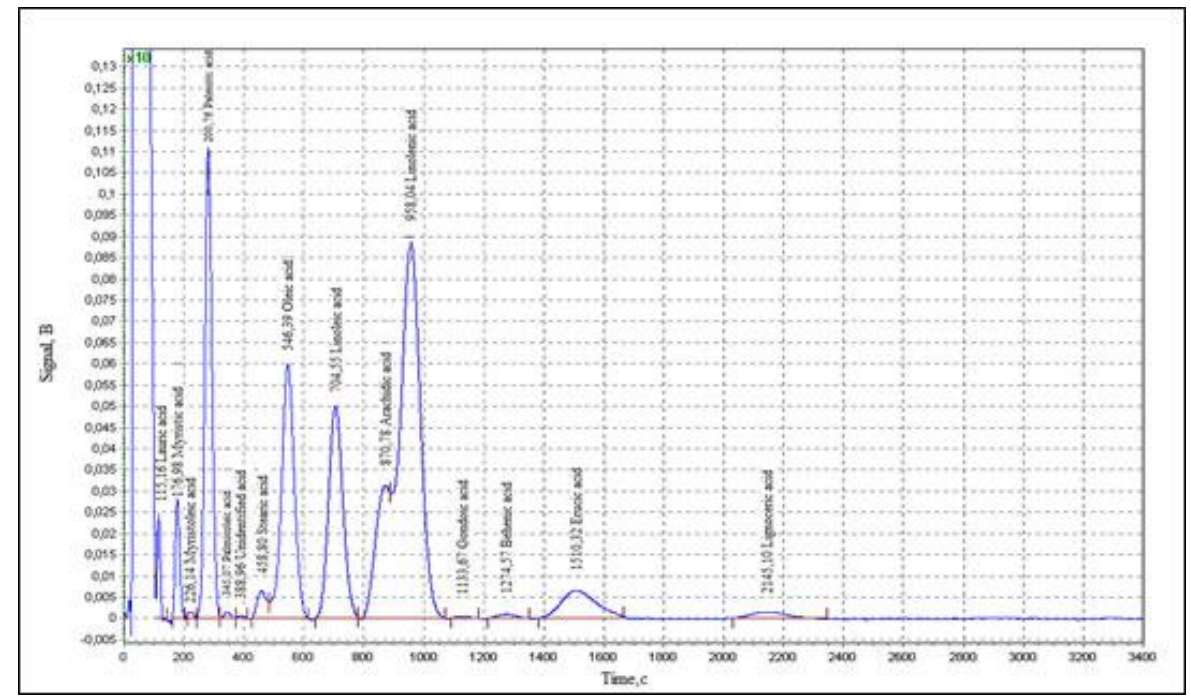

Fig. 2: Chromatographic profile of fatty acid methyl esters of Reynoutria sachalinensis leaves

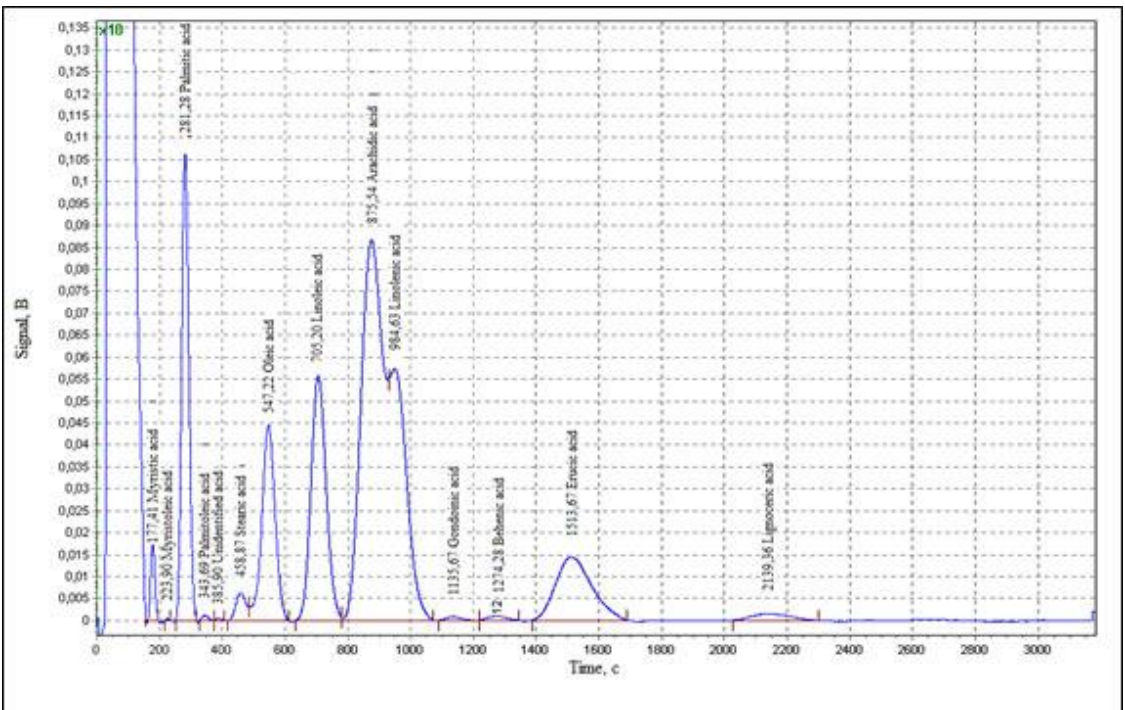

Fig. 3: Chromatographic profile of fatty acid methyl esters of Reynoutria sachalinensis herb

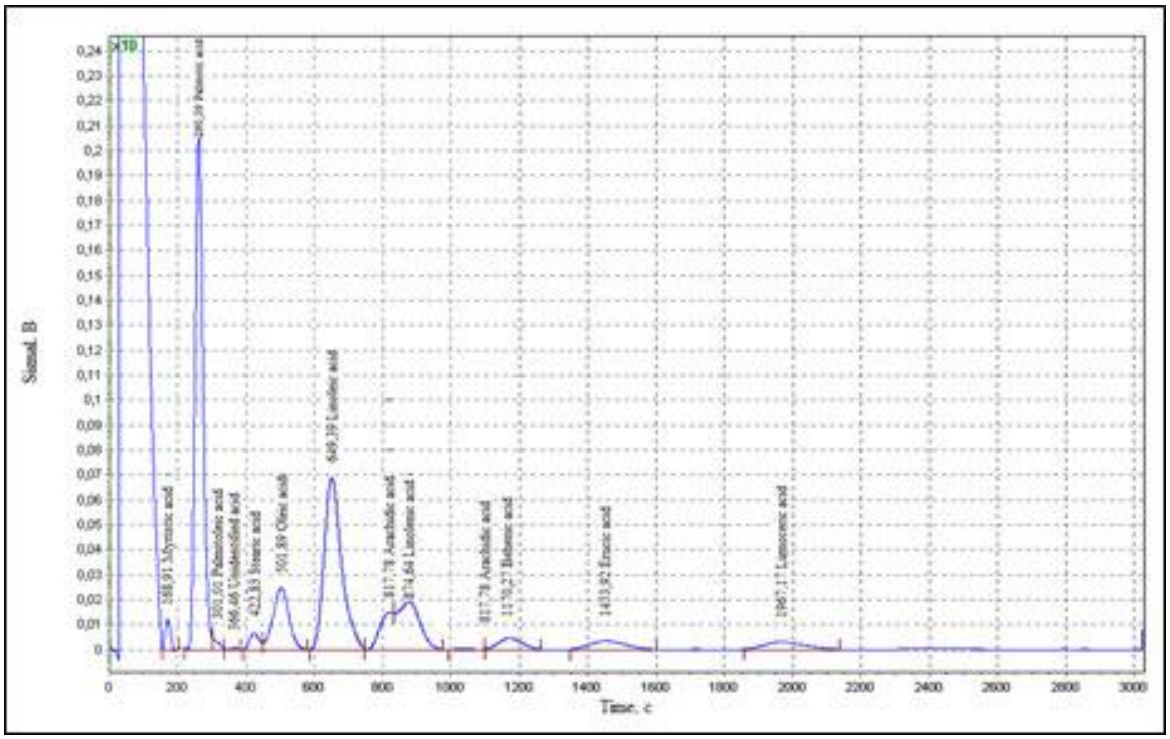

Fig. 4: Chromatographic profile of fatty acid methyl esters of Reynoutria sachalinensis flowers 
Table 1: The fatty acids content in Reynoutria sachalinensis plant raw material

\begin{tabular}{|c|c|c|c|c|}
\hline \multirow{2}{*}{$\begin{array}{c}\text { The name of the } \\
\text { acid }\end{array}$} & \multicolumn{4}{|c|}{ Content in terms of absolutely dry raw material, $\%$ of total amount } \\
\hline & Roots & Leaves & Herb & Flowers \\
\hline \multicolumn{5}{|c|}{ Saturated fatty acids } \\
\hline Lauric & - & $2.00 \pm 0.05$ & - & - \\
\hline Myristic & - & $2.95 \pm 0.07$ & $1.25 \pm 0.03$ & $1.55 \pm 0.04$ \\
\hline Palmitic & $16.00 \pm 0.40$ & $15.63 \pm 0.39$ & $12.27 \pm 0.31$ & $37.20 \pm 0.93$ \\
\hline Stearic & $1.18 \pm 0.03$ & $1.68 \pm 0.04$ & $1.22 \pm 0.03$ & $1.55 \pm 0.04$ \\
\hline $\begin{array}{l}\text { Arachidic } \\
\text { (icosanoic) }\end{array}$ & $1.67 \pm 0.04$ & $5.70 \pm 0.14$ & $37.05 \pm 0.93$ & $4.68 \pm 0.12$ \\
\hline Behenic & $0.25 \pm 0.01$ & $0.40 \pm 0.01$ & $0.32 \pm 0.01$ & $2.55 \pm 0.06$ \\
\hline Lignoceric & $0.78 \pm 0.02$ & $1.10 \pm 0.03$ & $1.00 \pm 0.03$ & $2.80 \pm 0.07$ \\
\hline $\begin{array}{l}\text { Total amount of } \\
\text { saturated fatty } \\
\text { acids }\end{array}$ & $19.88 \pm 0.50$ & $29.46 \pm 0.74$ & $53.11 \pm 1.33$ & $50.33 \pm 1.26$ \\
\hline \multicolumn{5}{|c|}{ Unsaturated fatty acids } \\
\hline Myristoleic & - & $0.08 \pm 0.01$ & $0.08 \pm 0.01$ & - \\
\hline Palmitoleic & $0.20 \pm 0.01$ & $0.18 \pm 0.01$ & $0.12 \pm 0.01$ & $0.72 \pm 0.02$ \\
\hline Oleic & $26.35 \pm 0.66$ & $14.85 \pm 0.37$ & $9.07 \pm 0.23$ & $8.75 \pm 0.22$ \\
\hline Linoleic & $40.90 \pm 1.02$ & $14.65 \pm 0.37$ & $13.32 \pm 1.13$ & $26.10 \pm 0.65$ \\
\hline Linolenic & $11.52 \pm 0.29$ & $37.20 \pm 0.93$ & $15.70 \pm 0.39$ & $11.10 \pm 0.28$ \\
\hline Gondoic & $0.12 \pm 0.01$ & $0.08 \pm 0.01$ & $0.22 \pm 0.01$ & $0.05 \pm 0.01$ \\
\hline Erucic & $0.85 \pm 0.02$ & $3.45 \pm 0.09$ & $8.30 \pm 0.21$ & $2.85 \pm 0.08$ \\
\hline $\begin{array}{l}\text { Total amount of } \\
\text { unsaturated fatty } \\
\text { acids }\end{array}$ & $79.94 \pm 2.00$ & $70.49 \pm 1.76$ & $46.81 \pm 1.17$ & $49.57 \pm 1.24$ \\
\hline $\begin{array}{l}\text { Total amount of } \\
\text { unidentified } \\
\text { acids }\end{array}$ & $0.18 \pm 0.01$ & $0.05 \pm 0.01$ & $0.08 \pm 0.01$ & $0.10 \pm 0.01$ \\
\hline
\end{tabular}

The quantitative content of identified fatty acids in Reynoutria sachalinensis plant raw material is presented in table 1 .

According to the results of the experiment, the content of unsaturated fatty acids in Reynoutria sachalinensis roots and leaves powder was $70-80 \%$ of their total content in raw material. Saturated and unsaturated fatty acids in herb and flowers powder of the studied plant were contained almost equally.

Among the saturated fatty acids in Reynoutria sachalinensis roots, leaves and flowers, palmitic acid (fig. 5) was the major compound and arachidonic acid (fig. 6) predominated in herb. The content of palmitic acid in roots, and leaves and herb of the studied plant ranged from 12.27 to $16.00 \%$. The maximum content of this compound was observed in Reynoutria sachalinensis flowers $37.20 \%$.

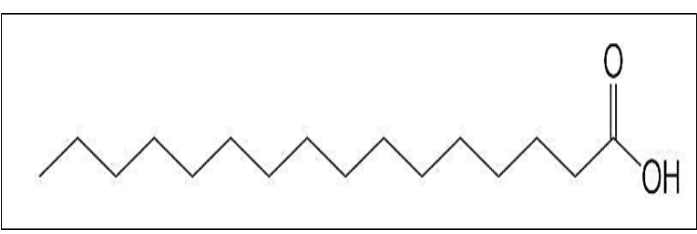

Fig. 5: The structure of palmitic acid

Arachidonic acid was the dominant saturated fatty acid in Reynoutria sachalinensis herb. The herb of the studied plant contained almost 6 times more of this compound than in other samples of plant raw material. The content of stearic acid in Reynoutria 
sachalinensis roots, leaves, herb and flowers did not differ significantly and was in the range of $1.18-1.68 \%$. At the same time, a relatively high content of lignocerinic $(2.80 \%)$ and behenic (2.55\%) acids was recorded in Reynoutria sachalinensis flowers, myristic $(2.95 \%)$ and lauric $(2.00 \%)$ - in the herb of this plant.

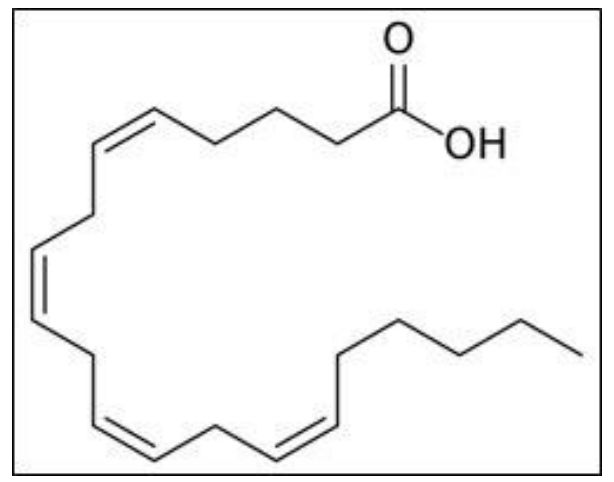

Fig. 6: The structure of arachidonic acid

Among the unsaturated fatty acids in Reynoutria sachalinensis roots and flowers, linoleic acid (fig. 7) dominated. The content of this compound in the roots $(40.90 \%)$ exceeded its content in flowers (26.10\%) 1.6 times. In addition, this plant raw material contained the most oleic acid (fig. 8) that equaled $26.35 \%$.

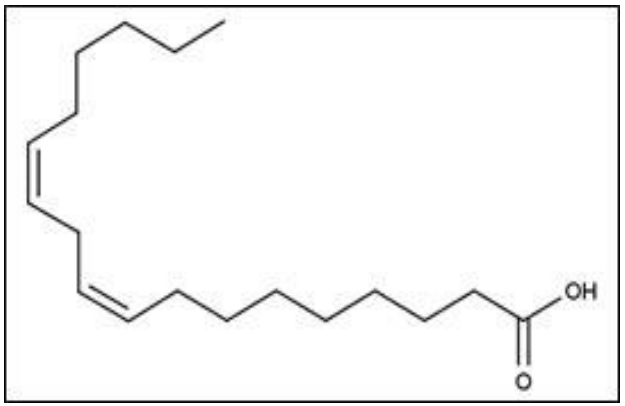

Fig. 7: The structure of linoleic acid

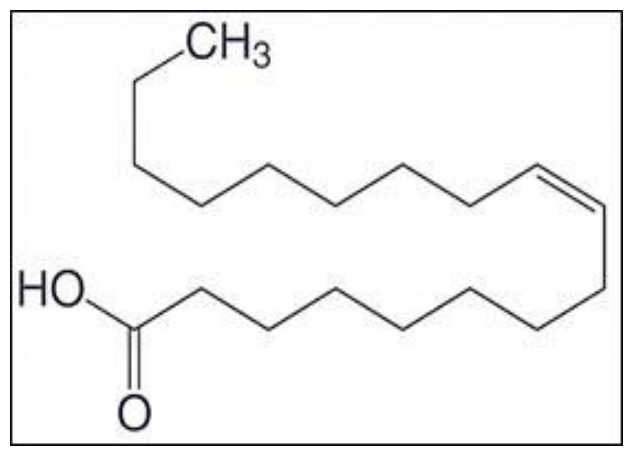

Fig. 8: The structure of oleic acid
Linolenic acid (fig. 9) prevailed in Reynoutria sachalinensis leaves and equaled $37.20 \%$. The content of oleic $(14.85 \%)$ and linoleic $(14.65 \%)$ acids in this plant raw material was almost at the same level.

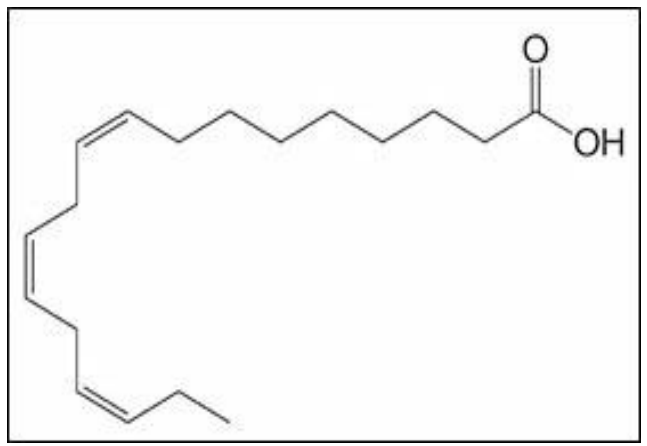

Fig. 9: The structure of linolenic acid

In Reynoutria sachalinensis herb, the content of linoleic and linolenic acids did not differ significantly and ranged from 13.32 to $15.70 \%$. Oleic acid in this plant raw material contained almost 1.5 times less - 9.07\%.

Erucic acid (fig. 10) was found in significant amount in Reynoutria sachalinensis herb and equaled $8.30 \%$. In leaves $(3.45 \%)$ and flowers $(2.85 \%)$ the content of this compound was almost three times lower.

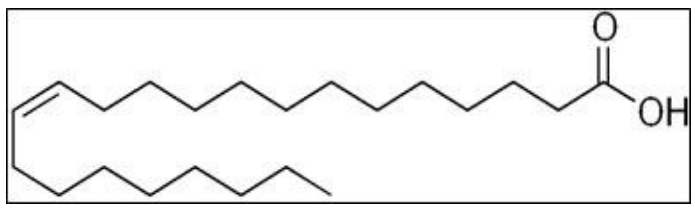

Fig. 10: The structure of erucic acid

The results of the experiment showed that the content of gondoic, myristoleic, palmitoleic acids in the studied types of plant raw material did not exceed $1 \%$.

The obtained results of the experiment do not contradict the literature data. The analysis showed that, unlike Reynoutria sachalinensis herb of Russian origin, Reynoutria sachalinensis herb of Ukrainian origin contained almost three times more palmitic acid and almost twice as much linoleic and linolenic acids. In addition, the content of myristic acid in Reynoutria sachalinensis herb, grown in Ukraine, was more than 10 times lower than the content of this compound in the specimen of foreign plant raw material. In addition, there is some difference in the qualitative composition of unsaturated fatty 
acids of Reynoutria sachalinensis herb of Ukrainian and Russian origin. Thus, Ukrainian samples contain gondoic and erucic acids, Russian - eicospentaenoic acid ${ }^{11}$.

\section{Conclusions}

12 to 14 fatty acids were identified in Reynoutria sachalinensis roots leaves, herb and flowers by gas chromatography. According to the results of the analysis, unsaturated fatty acids predominated in the roots and leaves of Reynoutria sachalinensis, where they contained $70-80 \%$. Saturated and unsaturated fatty acids accumulated almost equally in herb and flowers of this plant.

The results of the experiment showed that linoleic acid (40.90\%) dominated in Reynoutria sachalinensis roots, linolenic $(37.20 \%)$ - in leaves, the arachidonic $(37.05 \%)$ - in herb, palmitic $(37,20 \%)$ - in flowers. The content of linoleic and linolenic acids in Reynoutria sachalinensis herb was almost the same and did not exceed $15.70 \%$. In addition, this plant raw material has a high content of erucic acid that equaled $8.30 \%$.

The obtained results does not contradict the data of the literature, but some differences in the qualitative composition and quantitative content of fatty acids of Reynoutria sachalinensis of Ukrainian and Russian origin are noted. In particular, it was found that samples of Ukrainian origin have a more diverse qualitative composition of unsaturated fatty acids, the content of which is several times higher than their content in foreign samples.

The obtained results allow to deepen the knowledge about the fatty acid composition of the raw materials of Reynoutria sachalinensis, to establish the relationship between pharmacodiological action and the fatty acid composition of the raw materials, and will be used in the development of drugs based on it.

\section{REFERENCES}

1. C. M.Yates, Calder P. C., and G. Ed Rainger, "Pharmacology and therapeutics of omega-3 polyunsaturated fatty acids in chronic inflammatory disease", Pharmacol \& Therapeut, 141 (3), 272-
282 (2014).

2. A. C. Rustan and C. A. Drevon, "Fatty Acids: Structures and Properties", Encyclop of life science, 1, 1-7 (2005)

3. J. Lunn and H. E. Theobald, "The health effects of dietary unsaturated fatty acids", British Nutr Found Nutr Bull, 31, 178224 (2006).

4. Y. J. Al-shahery and I. N. Alasady, "Identification of Saturated and Unsaturated Fatty Acids Produced by Chlorella vulgaris as a Potential Candidate for Biodiesel Production", Trop J Nat Prod Res, 5 (2), 238-242 (2021).

5. J. Patocka, Z. Navratilova and $M$. "Ovando, "Biologically active compounds of Knotweed (Reynoutria spp.)", Mil Med Sci Lett, (Voj. Zdrav. Listy), 86 (1), 17-31 (2017).

6. H. Békési-Kallenbergera, G. Horvátha, T. Bencsika, V. L. Balázsa, R. Filepa and N. Pappa, "Comparative Histological and Phytochemical Study of Fallopia species", Natural Product Commun, 11 (2), 251254 (2016).

7. G. Li and Y. "Ishikawa, Leaf Epicuticular Wax. Chemicals of the Japanese Knotweed Fallopia japonica as Oviposition Stimulants for Ostrinia latipennis", Jof Chem Ecol, 32 (3), 595604 (2006).

8. S. Lachowicz and J. Oszmianski, "Profile of Bioactive Compounds in the Morphological Parts of Wild Fallopia japonica (Houtt) and Fallopia sachalinensis (F. Schmidt) and Their Antioxidative Activity", Mol, 24, 14361451 (2019).

9. V. Titei, N. Cirlig, M. Stavarache, A. Gutu and S. Cosman, "Some biological features and the biochemical composition of Polygonum sachalinense in Moldova", Res J of Agricult Sci, 50 (3), 26-32 (2018).

10. V. Metlicar, I. Vovk and A. Albreht, "Japanese and Bohemian Knotweeds as Sustainable Sources of Carotenoids", Plants, 8, 384-399 (2019).

11. N. N. Karsukova Biological resources Polygonum sachalinense F. Schmidt as a raw material for biotechnological industries: PhD thesis. Vladikavkaz, 2014. 
12. I. Nawrot-Hadzik, S. Granica, K. Domaradzki, Ł. Pecio and A. Matkowski, "Isolation and Determination of Phenolic Glycosides and Anthraquinones from Rhizomes of Various Reynoutria Species", Planta Med, 1, 1-9 (2018).

13. "European Pharmacopoeia. $9^{\text {th }} \quad$ ed.," Strasburg, France: European Directorate for the Quality of Medicines, 2017.

14. O. A. Kyslychenko, V. V. Protska, I. O. Zhuravel and V. V. Hutsol, "The study of Daucus carota subsp. sativus fruits fatty acid composition of «Olenka», «Kharkivska Nantska» and «Yaskrava» varieties", Res J of Pharm Biol and Chem Sci, 9 (6), 307-312 (2018).
15. M. F. Dababneh, V. V. Protska and I. O. Zhuravel, "Analysis of fatty acid composition of rhizomes with roots, leaves and flovers of Hosta Plantaginea", Res J of Pharm, Biol and Chem Sci, 7(6), 2251- 2255 (2016). 


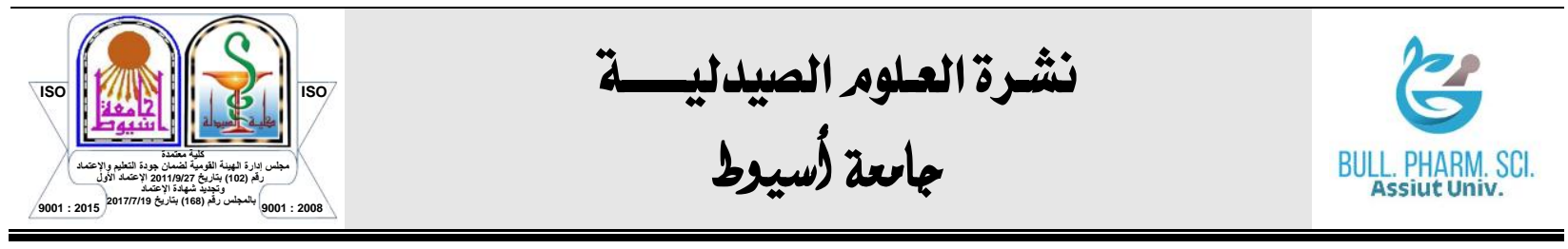

\section{در اسة مكونات الحمض الاهنى فى نبات رينوتريا ساتشينينسيس المادة الخام}

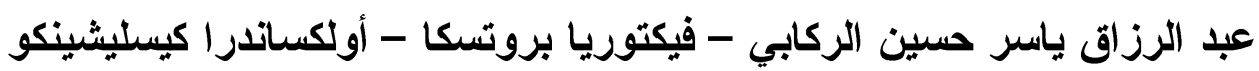
إيرينا زور افيل

قسم كيمياء المركبات الطبيعية وعلم التغذية ، الجامعة الوطنية للصيدلة ، خاركيف ، أوكرانيا

الهدف دراسة التركيب النوعي وتحديد المحتوى الكمي للأحماض الدهنية للجذور و الأوراق

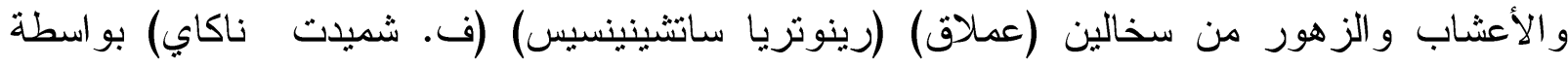

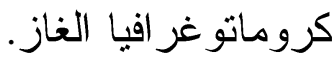

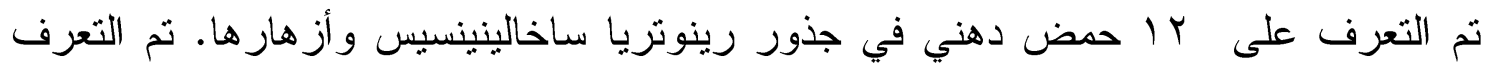

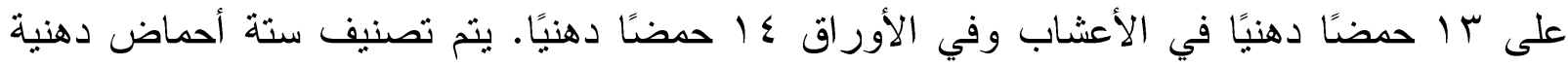

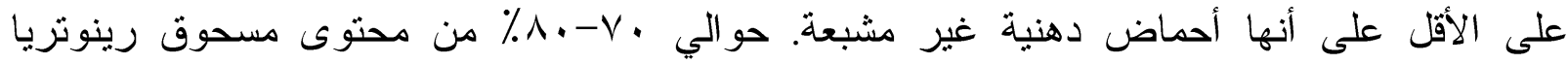

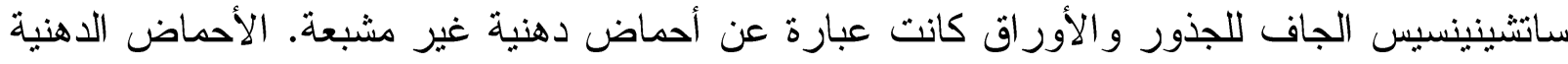

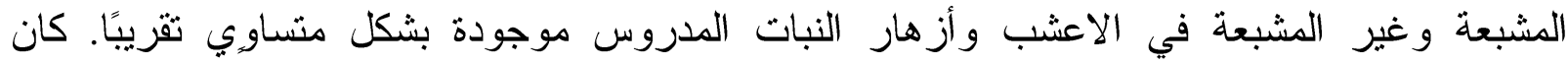

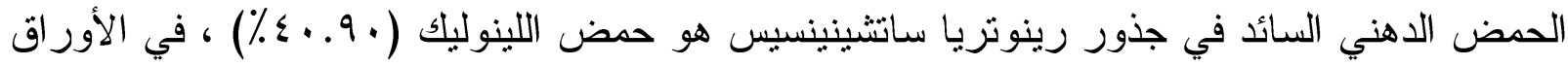

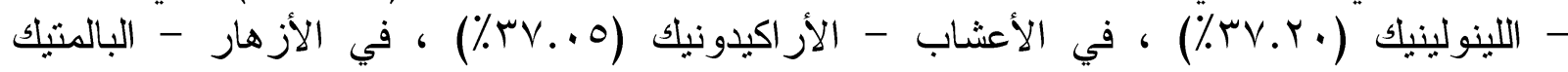

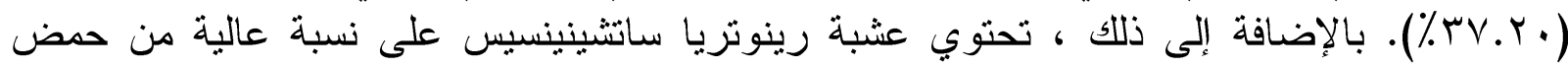

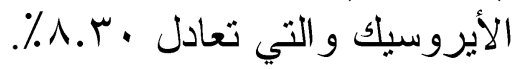

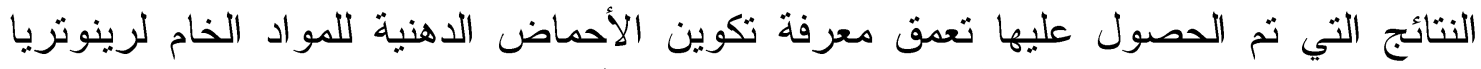
ساتثينينسيس ، لإثبات العلاقة بين التأثير الدوائي وتكوين الأحماض الدهنية للمواد التهاد الخام ، وسيتم استخدامها في نطوير الأدوية القائمة عليها. 